\title{
ORGANIZAÇÃO E REGULAÇÃO DOS ENSINOS BÁSICO E SECUNDÁRIO, EM PORTUGAL: SENTIDOS DE UMA EVOLUÇÃO
}

\author{
JoÃo BARRoso
}

\begin{abstract}
RESUMO: No presente artigo proponho-me caracterizar a evolução recente do sistema educativo português (no nível dos ensinos básico e secundário) tomando como referência as transformaçōes ocorridas nos processos de organização e regulação dos seguintes domínios: currículo, oferta escolar, recrutamento e formação de professores, gestão escolar e recursos financeiros, partenariado socio-educativo. Como eixo central de análise utiliza-se o conceito de "regulação institucional" como intervenção das autoridades públicas para introduzir "regras" e "constrangimentos" no mercado ou na acção social. O objectivo do presente texto consiste, por isso, em utilizar a evolução dos modos de regulação como analisador das transformações recentes do sistema educativo português, pondo em destaque a coexistência de medidas de reforço da autonomia das escolas e de novas formas de controlo, bem como a sua inserção nas políticas de combate às desigualdades escolares. Serão analisados, igualmente, os sentidos que essas medidas assumem num contexto de mudança global dos modos de regulação da educação, que ocorre em vários países, tendo em vista a redefinição do papel do "Estado educador" e a emergência de uma "regulação pelo mercado".
\end{abstract}

Palavras-chave: Regulação da educação. Políticas educativas. Reformas da educação em Portugal.

\section{ORGANIZATION AND REGULATION IN THE PORTUGUESE EDUCATIONAL SYSTEM (AT BOTH PRIMARY AND SECONDARY LEVEL)}

ABSTRACT: Taking as its starting point the changes in the regulation and organization processes of such fields as curriculum, school provision, teacher training and recruitment, school management and financial resources and socio-educational partnership, this paper de* Professor da Faculdade de Psicologia e de Ciências da Educação da Universidade de Lisboa.
E-mail: jbarroso@fpce.ul.pt 
scribes the recent evolution of the Portuguese educational system (at both primary and secondary level). This analysis is centered on the concept of "institutional regulation", understood as the intervention of public authorities to produce "rules" and "constraints" either on the market or in the social action. Thus, the main goal is to use the regulation mode evolution to analyze the recent changes that have affected the Portuguese educational system, highlighting the coexistence of political measures that reinforce school autonomy and of new forms of control and school inequality. The meaning of these political measures will also be analyzed within context of the global changes of the regulation modes in education that are taking place in several countries, which promote a redefinition of the role of the "State as Educator" and the emergence of a "market regulation".

Key words: Regulation of education. Educational policies. Portuguese educational reforms.

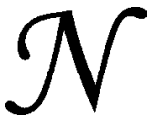

o presente artigo proponho-me caracterizar a evolução recente do sistema educativo português (no nível dos ensinos básico e secundário ${ }^{1}$ ) tomando como referência as transformações ocorridas nos processos de organização e regulação dos seguintes domínios: currículo, oferta escolar, recrutamento e formação de professores, gestão escolar e recursos financeiros, partenariado socio-educativo. Como eixo central de análise utiliza-se o conceito de "regulação institucional" definida como "o conjunto de acçôes decididas e executadas por uma instância (governo, hierarquia de uma organização) para orientar as acçôes e as interacçôes dos actores sobre os quais detém uma certa autoridade" (Maroy \& Dupriez, 2000). Esta definição põe em evidência, no conceito de regulação, as dimensões de coordenação, controlo e influência exercidas pelos detentores de uma autoridade legítima, sendo por isso próxima da acepção que prevalece na literatura americana (no domínio da economia, mas também da educação) como intervenção das autoridades públicas para introduzir "regras" e "constrangimentos" no mercado ou na acção social.

O objectivo do presente texto consiste, por isso, em utilizar a evolução dos modos de regulação como analisador das transformações recentes do sistema educativo português, pondo em destaque a coexistência de medidas de reforço da autonomia das escolas e de novas formas de controlo, bem como a sua inserção nas políticas de combate às desigualdades escolares. Esta análise tem como principal suporte a investigação realizada sobre a evolução dos modos de regulação institucional do sistema educativo em Portugal (Barroso et al., 2002), no âmbito de um projecto internacional que envolve, além 
da equipa portuguesa (que coordeno), equipas universitárias de França, da Comunidade francófona da Bélgica, da Hungria e do Reino Unido (Inglaterra). ${ }^{2}$ De acordo com este objectivo o artigo se encontra estruturado em três pontos:

Num primeiro ponto, irei apresentar uma breve panorâmica da evolução das políticas educativas em Portugal, após a instauração do regime democrático em 1974, identificando os "ciclos de mudança" política e as principais medidas tomadas no domínio da organização e regulação do sistema.

Num segundo ponto, apresento uma descrição sumária dos processos de regulação institucional, actualmente existentes, no domínio do currículo, da oferta escolar, do recrutamento e da formação de professores, da gestão escolar e dos recursos financeiros, e do partenariado socio-educativo, com a finalidade de pôr em destaque a coexistência de medidas de reforço da autonomia das escolas e de novas formas de controlo, bem como a sua inserção nas políticas de combate às desigualdades escolares.

Finalmente, num terceiro ponto, apresentarei uma breve síntese sobre os sentidos que essas medidas assumem num contexto de mudança global dos modos de regulação da educação, que ocorre em vários países, tendo em vista a redefinição do papel do "Estado educador" e a emergência de uma "regulação pelo mercado". A este propósito será analisado o efeito de contaminação que existe no nível da transferência dos conceitos, das políticas e das medidas postas em prática, entre os países, em escala mundial.

\section{Os ciclos de mudança política}

A evolução recente do sistema educativo português está indelevelmente marcada pela mudança do regime político em abril de 1974 e pelas consequências que o restabelecimento da democracia e o processo histórico posterior provocaram em todos os sectores da vida social. Esta evolução constitui um campo de estudo ainda em construção, mas para o qual existem já contributos significativos de vários autores, quer centrados na descrição e análise de aspectos sectoriais da organização e do funcionamento do sistema educativo, ${ }^{3}$ quer orientados para uma interpretação global e diacrónica da política educativa nesse período. ${ }^{4}$

No âmbito do presente texto e tendo em conta os seus objectivos justifica-se, por isso, situar a apresentação da organização e regulação do sistema educativo português à luz do contexto histórico recente. 
Neste sentido se apresenta de seguida (e de modo abreviado) uma síntese interpretativa do processo de construção institucional do nosso sistema educativo após a instauração do regime democrático (19742002), pondo em destaque o sentido das políticas que orientaram a sua organização e as principais medidas tomadas nos diferentes domínios que são objecto deste estudo.

Essa evolução é descrita em função de quatro grandes ciclos temporais, organizados de acordo com a dinâmica social dos processos de mudança e do leitmotif das políticas educativas que lhes estiveram subjacentes: revolução, normalização, reforma e descontentamento. ${ }^{5}$

\section{Revolução}

O primeiro ciclo - revolução - abrange o período que se inicia com o golpe militar de " 25 de abril de 1974 " e se extingue progressivamente com a posse do primeiro governo constitucional, em 1976. É um período dominado pelo "processo revolucionário em curso", de forte participação social, por vezes espontânea e radical, mas quase sempre instrumentalizada pelas vanguardas partidárias, empenhadas em eliminar (ou esconder) os vestígios do passado anti-democrático e em disputar a primazia na definição de um modelo futuro.

É um período de grande instabilidade política (traduzida pela drástica redução da capacidade de intervenção do Estado e por uma acesa disputa de liderança partidária entre o partido comunista e partidos situados à sua esquerda, por um lado, e o partido socialista e partidos situados à sua direita, por outro) e de intensa mobilização cívica e social que afectou todos os sectores da sociedade. No domínio da educação assiste-se, fundamentalmente, a dois movimentos:

- Uma tentativa institucional (conduzida pelos vários responsáveis no Ministério da Educação, dos diferentes governos provisórios) para conceber e aplicar mudanças educativas que, do ponto de vista simbólico e formal, estabelecessem uma ruptura clara com a "ideologia fascista" e, ao mesmo tempo, garantissem a governabilidade do sistema e configurassem um modelo educativo emergente, adequado à construção de uma "democracia socialista".

- Um movimento social muito diversificado e descentrado que punha em causa a lógica reformista do Estado, antecipando-se aos seus desígnios e consumando as mudanças independentemente de qualquer alteração dos normativos. 
Como refere a este propósito António Teodoro (2001a), no estudo que consagrou à construção das políticas educativas nesse período:

O poder deslocava-se para as escolas (Lima, 1992; Stoer, 1986) e para o movimento social, onde as nascentes estruturas sindicais dos professores começavam já a assumir um papel de destaque no campo escolar, estabelecendo-se uma agenda que não era compaginável com uma transição controlada. As demissões em massa das autoridades académicas e escolares e a eleição de comissões directivas com a participação de docentes, estudantes e funcionários, a imediata integração dos professores afastados pelo Estado Novo, a exigência de profundas mudanças no aparelho do Ministério da Educação, mostravam que a iniciativa política se encontrava na periferia do sistema. Às formulações vagas e cautelosas tanto do Programa do MFA [movimento que conduziu o golpe militar] como do Programa do Governo Provisório, o movimento social (e político) respondia com o uso, sem limites, das liberdades de associação e expressão, impondo soluções na prática antes de qualquer legislação. (P. 347)

O balanço que é feito desse período varia conforme o posicionamento político dos seus autores e vai desde uma análise mais optimista, que põe em relevo algumas das "conquistas revolucionárias" mais significativas, a uma análise mais catastrofista, que sublinha essencialmente a "ingovernabilidade" reinante, o carácter voluntarista, casuístico e pernicioso das mudanças.

Rui Grácio, um notável pedagogo português que se evidenciara na oposição ao regime anterior e que teve uma intervenção cívica e política importante nesse período (tendo sido secretário de Estado em dois governos provisórios), faz um balanço "francamente positivo", "apesar das sombras e excessos, tanto da fase revolucionária, ou pré-revolucionária, como da que se lhe seguiu". Entre os traços mais significativos desse balanço Grácio (1995, p. 476-478) aponta: "A alteração em todos os graus e ramos de ensino dos conteúdos e das aprendizagens" (para desembaraçá-los "dos valores típicos da ideologia fascista" e modernizálos do ponto de vista científico e cultural, preservando os princípios de pluralismo ideológico e inspiração democrática); "dignificação do estatuto pedagógico, social e cívico do professorado" (no domínio da autonomia pedagógica, da revalorização salarial, da participação na gestão e na liberdade sindical); "transformação das relações institucionais no aparelho de ensino" (libertando-o de "formas repressivas de autoritarismo e mandarinato político, administrativo e pedagógico, bem como de algum pessoal docente e outro que as encarnava"); "modificação dos objectivos propostos ao sistema de ensino nas suas relações com a sociedade global" 
(com o fim de romper o seu isolamento e a subordinação a interesses de "minorias sociais" e de abrir as escolas à realidade envolvente); "cooperação do sistema de ensino na democratização social, procurando alterar a sua função de reprodução e legitimação das desigualdades sociais e regionais" (o que se traduziu, essencialmente, em: medidas compensatórias de ordem pedagógica e social, unificação das diferentes vias do ensino básico e secundário, "discriminação positiva a favor dos trabalhadores e seus filhos").

Contrastando com este balanço, Magalhães Godinho, que foi ministro da Educação no mesmo período e que se demitiu por considerar que não tinhas condiçôes para governar, afirma:

(...) deu-se a atomização do ensino, em grande número as escolas tornaramse pequenos reinos independentes, legislando para si próprias, a embriaguez natural das reuniôes de massa paralisou frequentemente o seu funcionamento e caiu-se na facilidade (...). Por seu lado, o Ministério não dispõe dos meios de acção para enfrentar tal situação de emergência de maneira adequada, está paralisado por uma legislação e um conjunto de órgãos obsoletos e emperrados. (Godinho, 1975, p. 26)

\section{Normalização}

Com a aprovação da Constituição, a realização das primeiras eleições legislativas (que confirmam a maioria, ainda que relativa, do Partido Socialista e a perda de influência eleitoral do Partido Comunista e de outras forças políticas à sua esquerda) e a nomeação do primeiro governo constitucional, inicia-se um novo ciclo, marcado por uma política deliberada de "normalização"6 do funcionamento do sistema educativo. Esse período se estende até 1986, com a aprovação da Lei de Bases do Sistema Educativo, ${ }^{7}$ ano em que, igualmente, processa-se a integração de Portugal na, então designada, Comunidade Europeia.

O objectivo fundamental dessa política consiste em recuperar o poder e o controlo do Estado e sua administração sobre a educação, eliminando as "derivas revolucionárias", afastando os que eram considerados seus principais agentes no aparelho do Ministério da Educação e introduzindo critérios de "racionalidade técnica" na decisão política, nomeadamente, por meio do reforço das estruturas e dos processos de planeamento.

Esse período é marcado por uma acentuada crise financeira (com a dívida pública a atingir $90 \%$ do produto interno bruto, em 1984 , e a 
inflação a atingir os 20\%) e pela intervenção do Fundo Monetário Internacional e do Banco Mundial.

De acordo com Teodoro (2001a, p. 389) a normalização da política educativa conheceu dois movimentos: um primeiro por meio de "intervenções negativas" destinadas a afastar do Ministério da Educação os quadros "que personalizavam o conjunto das principais orientações e reformas encetadas durante o período da crise revolucionária” e a eliminar, ou atenuar, os efeitos das medidas entretanto tomadas; um segundo movimento, destinado a criar condições para enfrentar o "desafio europeu”, por intermédio de medidas de política educativa orientadas essencialmente para a contenção do acesso ao ensino superior universitário (criação do numerus clausus em 1977), diversificação de vias de ensino nos estudos pós-secundários (criação do ensino superior curto politécnico, no mesmo ano), desenvolvimento do ensino técnico-profissional, principalmente a partir de 1983. Essa política se integra no que alguns autores designam por "novo vocacionalismo", associando a oferta de recursos humanos qualificados, segundo as exigências do mercado de trabalho, à modernização da economia e atribuindo ao Estado a função de disponibilizar um sistema educativo adequado a este desígnio (Stoer, Stoleroff \& Correia, 1990). Como assinala Correia (1999), referindo-se à política educativa em Portugal, na década de 1980:

Seguindo uma tendência geral dos países capitalistas, assistiu-se ao aparecimento no campo educativo de um conjunto de discursos mais ou menos congruentes em que, como realça $\mathrm{M}$. Apple, as preocupações com a eficácia, os padrōes de qualidade e a formação para o trabalho se sobrepuseram às preocupações "com o currículo democrático, com a autonomia do professor ou com a desigualdade de classe, de raça ou de género" (1986, p. 29), ou seja, onde o binómio educação/modernização do tecido produtivo ocupou o lugar do binómio educação/democracia. (P. 89-90)

\section{Reforma}

O terceiro ciclo temporal em que se divide a evolução da educação, em Portugal, após a instauração do regime democrático, vai ser dominado pela ascensão e queda do "mito da reforma" (ver Barroso, 2000) e estende-se de 1986 até final do século XX. ${ }^{8}$

Na verdade, a aprovação, em 1986, da Lei de Bases do Sistema Educativo "permitiu fechar o ciclo da normalização da política educativa e abrir uma nova fase, centrada novamente no propósito de realizar a 
reforma educativa" (Teodoro, 2001a, p. 399). Como eu próprio escrevia, nessa altura, a propósito da aprovação deste diploma:

Singularmente, e apesar das polémicas inflamadas que em muitos casos suscitaram, a maior parte das transformaçōes estruturais, introduzidas (ou desenvolvidas) no pós- 25 de abril, acabaram por ser aprovadas pela grande maioria dos deputados e consagradas na Lei de Bases. É o caso, entre outros, da unificação do ensino secundário geral, do prolongamento do ensino secundário complementar, do ensino superior politécnico, da criação das escolas superiores de educação, dos modelos de gestão democrática das escolas etc. A única grande novidade (mas que na prática já constituía um dado adquirido e quase inevitável) foi o prolongamento da escolaridade obrigatória para 9 anos. (...) A Lei de Bases tem que ser vista, assim, como o coroar de um processo de transformaçóes não-lineares, que ocorreram desde o " 25 de abril". Ela veio fixar, sob a forma de diploma legal, um quadro normativo amplo e coerente que estabelece a organização e as estruturas do sistema educativo e que define os princípios gerais que deverão informar a legislação complementar, a publicar pelo governo, no prazo de um ano (como prescreve a própria Lei). (Barroso, 1987, p. 12-13)

O "ciclo da reforma" pode dividir-se em dois grandes períodos: o primeiro é protagonizado pelo ministro Roberto Carneiro que integra um governo do Partido Social-Democrata (centro-direita), entre 1987 e 1991; o segundo é protagonizado pelo ministro Marçal Grilo que integra um governo do Partido Socialista (centro-esquerda), entre 1996 e 2000 .

O primeiro período é dominado claramente por um certo "messianismo reformista" (Barroso, 1988) que reforça os aspectos emblemáticos e míticos de uma reforma global, a qual, segundo os seus promotores, viria resolver, finalmente, os problemas da educação e criar o "homem novo". A reforma é concebida e desenvolvida segundo um modelo normativo-dedutivo, fundado numa concepção determinista da mudança, conduzida do topo para a base do sistema (top - down), com o reforço dos dispositivos de planeamento e legitimada politicamente por um discurso "modernizador" tendo em vista assegurar a integração plena de Portugal na Comunidade Europeia (Barroso, 1988).

De entre um conjunto variado de medidas tomadas nesse período (muitas delas destinadas a pôr em prática e a regulamentar a Lei de Bases do Sistema Educativo) são de destacar, pelo seu significado político, as seguintes: uma contenção do acesso ao ensino superior público e um forte estímulo à abertura de estabelecimentos de ensino superior privado; a criação das "escolas profissionais" (que configuram 
uma modalidade inovadora de tutela mista, entre o Ministério da Educação e outros promotores públicos ou privados) ${ }^{10}$ o reforço de dispositivos de avaliação (início da avaliação do ensino superior, introdução da avaliação aferida dos alunos, criação de um "observatório de qualidade das escolas" etc.).

Segundo Almerindo Afonso (1997) essas medidas configuram a existência em Portugal, no período correspondente aos governos apoiados pelo Partido Social-Democrata (centro-direita), entre 1985 e 1995 ,

de um neoliberalismo educacional mitigado, resultante [mais] das pressões contraditórias exercidas pelos diferentes grupos e classes sociais que participaram, directa ou indirectamente, na definição da política educativa, do que no sentido da assunção inequívoca de todos os traços e dimensões que, em outros países, têm sido considerados expressivos e definidores das políticas da nova direita. (P. 122)

O segundo período deste "ciclo da reforma" decorre entre 1996 e 2000 e corresponde à vigência de um governo do Partido Socialista que sucedeu a dez anos de governação social-democrata. De um ponto de vista retórico o novo ministro da educação, Marçal Grilo, procurou demarcar-se da estratégia reformista anterior, substituindo-a por uma política de "geometria variável" assente, supostamente, na clareza e consensualidade dos princípios e na flexibilidade da acção. Como instrumento essencial dessa política, o ministro apresentou em 1996 ao Parlamento, às escolas e aos diferentes "parceiros educativos" um Pacto Educativo para o Futuro. Este documento era constituído por um conjunto de princípios, objectivos estratégicos e compromissos, apresentados como "bases essenciais para a acção política e para o relacionamento com todos os protagonistas do processo educativo", visando a "pacificar a educação" e assegurar "um acordo sobre os grandes rumos da política educativa” (Teodoro, 1996). Contudo, em virtude das condições políticas (governo sem maioria absoluta) e da própria ambiguidade do seu conteúdo, o Pacto não encontrou grande eco na opinião pública e o "acordo" não chegou a firmar-se (Barroso, 1996).

Esta situação não impediu que fossem tomadas diversas medidas que deram continuidade à reforma anterior (nos domínios da revisão curricular, da gestão das escolas, da formação de professores, da avaliação dos alunos etc.), ao lado de outras, mais pontuais, que pretendiam marcar a diferença de um governo socialista, simultanea- 
mente preocupado com a "qualidade" e a "igualdade de oportunidades", como sejam: criação dos Territórios Educativos de Intervenção Prioritária [TEIP] (equivalentes das ZEP francesas); medidas de pedagogia compensatória (currículos alternativos, apoio pedagógico assistido); ${ }^{11}$ forte impulso à expansão da educação pré-escolar; generalização da avaliação aferida; avaliação das escolas; internet nas escolas.

Todo este movimento reformista (quer no primeiro quer no segundo período) foi fortemente apoiado por um substancial reforço financeiro, no âmbito do Quadro Comunitário de Apoio negociado com a Comissão Europeia e que se traduziu no Programa de Desenvolvimento Educativo para Portugal (PRODEP). Esse Programa tinha como objectivo "preparar o sistema educativo português para as exigências económicas e sociais decorrentes do processo de integração europeia", por intermédio dos seguintes vectores estratégicos: "generalizar o acesso à educação; modernizar as infra-estruturas e melhorar a qualidade da acção educativa". Previsto inicialmente para o período de 1990-1993, foi sucessivamente prolongado por duas vezes (1994-1999 e 2000-2006). A maior parte dos investimentos efectuados diz respeito à construção de escolas e melhoria dos equipamentos educativos (centros de recursos, instalaçōes desportivas, informática etc.), bem como ao financiamento de acçốes de formação contínua de professores (Programa Foco). ${ }^{12}$

\section{Descontentamento}

O início do século XXI marca a entrada num novo ciclo evolutivo cujos contornos ainda pouco se conhecem, mas que nesta fase é marcado fundamentalmente pela manifestação (vinda de diferentes sectores sociais e por diferentes razões) de um claro descontentamento quanto à situação em que se encontra a educação em Portugal.

A percepção de que a educação é um "sector em crise" tem sido uma constante, antes e depois da instauração do regime democrático em 1974. Contudo, o que é significativo deste novo período é a passagem de um sentimento de uma "crise de problemas" para o de uma "crise de soluções".

Acabada a euforia da Reforma em que se empenharam os dois maiores partidos do espectro político português e depois de 25 anos de transformaçôes contínuas, apoiadas por fortes investimentos financeiros, responsáveis por uma elevada taxa de crescimento de alunos, professores e escolas, o diagnóstico que é feito sobre o desempenho do sistema e das 
escolas é, em muitos casos, pouco animador, oscilando entre a "desilusão" e a "catástrofe".

Roberto Carneiro, que coordenou recentemente um estudo de reflexão prospectiva $O$ futuro da educação em Portugal: tendências e oportunidades, ${ }^{13}$ faz assim o balanço da situação actual:

O progresso educativo foi, a muitos títulos, impressionante. A escolarização de crianças e jovens conheceu um desenvolvimento exponencial. Temos hoje, na prática, $100 \%$ de cada coorte geracional integrada no ensino básico [até ao $9^{\circ}$ ano de escolaridade], cerca de $70 \%$ retida até ao final do secundário [até ao $12^{\circ}$ ano de escolaridade] e mais de $30 \%$ a frequentar estudos pós-secundários. São indicadores que, sem margem para dúvidas, comparam bem com as médias estatísticas da União Europeia. O parque escolar - desde o pré-escolar ao universitário - cresceu de forma espectacular, cobre de forma mais harmoniosa o território, e obedece a critérios de qualidade compatíveis com padrões internacionais. A esmagadora maioria dos nossos professores e educadores é profissionalizada. $\mathrm{O}$ ensino superior que estava, há apenas 30 anos, concentrado em três cidades universitárias encontra-se hoje disponível em todas as capitais de distrito, nas regiōes autónomas, e ainda num grande número de outras localidades que sustentam uma nova muralha urbana do país em formação. (...).

Todavia, estes inquestionáveis avanços confrontam-se com persistentes problemas que constituem o reverso da medalha. Nas avaliaçôes padronizadas que passaram a ser regularmente conduzidas por organismos internacionais, os nossos resultados são preocupantes: seja em matéria de literacia, seja no que respeita a conhecimentos de matemática e de ciências, os nossos jovens situam-se, por via de regra, na cauda dos países. Verifica-se uma sistemática condenação por parte de cada nível de ensino relativamente ao "produto aluno" que lhe é entregue pelo nível imediatamente precedente. Constatamse manifestas disfunçôes entre as novas necessidades do mercado de trabalho e as ofertas tradicionais de diplomados. Acima de tudo a sociedade e a economia portuguesa continuam a assentar numa população adulta - activa que, em contraste com as novas geraçôes, não conseguiu ir muito mais além do que os seis anos de escolaridade formal. (Carneiro, 2000, p. 34-35)

Trata-se de um balanço no qual se pretende contrastar as questóes da "quantidade" e da "qualidade" e que abre para uma perspectiva de desenvolvimento do sistema educativo, moldada no objectivo de "recuperar o atraso que nos separa dos nossos parceiros europeus", em que, depois de se ter apostado na quantidade, "chegou a hora de apostar na qualidade”. Como diz a este propósito Rui Canário:

Aceitar sem discussão esse pressuposto [de que somos um "país atrasado"] significa aceitar transferir para a educação a crença "ocidental" no "progresso", 
tendo como referente o modelo de "desenvolvimento" cujo apogeu se situou nos "trinta anos gloriosos" que marcaram o pós-guerra. Implica ainda aceitar, sem crítica, uma relação linear e positiva entre educação e "desenvolvimento" (...). (Canário, 1998, p. 15)

Esta insistência na "qualidade" e a omissão (em hora de balanço) das questões da equidade e da igualdade de oportunidades são reflexos claros de um movimento de opinião e de intervenção política que, principalmente, a partir dos meados dos anos de 1980, tem vindo a insistir no discurso da "modernização" e "competição", substituindo-o pelo da exigência da "democracia" e da "igualdade de oportunidades".

É neste contexto que se assiste hoje, em Portugal, no quadro de uma "crise de soluções" gerada pela queda do mito da reforma educativa, à promoção, na comunicação social e junto de largos sectores da opinião pública, de um diagnóstico catastrofista sobre a situação em que se encontra o nosso sistema educativo. Sob um aparente consenso apartidário, esse diagnóstico pretende abrir caminho à aceitação pela opinião pública de propostas de cariz "neo-liberal”, como sejam a privatização do ensino, a subordinação da educação à lógica de mercado, com a livre escolha da escola pelos pais, a competição interescolas etc., misturadas com outras de cariz mais conservador, como o primado das "aprendizagens fundamentais" (back to basic), o reforço da autoridade, do rigor e da disciplina (ver a este propósito Pacheco, 2000; Lima \& Afonso, 2002; Estêvão, 2002; Barroso, 2003).

A mudança de governo, no início de 2003, com a subida ao poder de uma coligação de centro-direita, abriu caminho para a adopção de uma política educativa que vai nesse sentido. Até ao momento, no sector da educação, ainda não foram adoptadas medidas de fundo, mas, a exemplo do que acontece em outros sectores, parece existir uma estratégia de redução da intervenção do Estado na regulação e prestação do serviço educativo, com a promoção de um "mercado da educação" e adopção de critérios e modalidades de gestão empresarial. Contudo, a situação ainda não está suficientemente clarificada, pelo que ainda é prematuro prever qual será a evolução deste "ciclo de descontentamento" e como será resolvida, em Portugal, a crise do "Estado educador": se por meio de uma mera subordinação à "lógica de mercado", emergente no contexto do modelo (até agora dominante) de "globalização", ou se pelo aprofundamento de alternativas socio-comunitárias que ultrapassem a dicotomia Estado-mercado (Barroso, 2001, 2003). 


\section{A regulação institucional}

A alteração dos modos de regulação institucional, na definição e aplicação das políticas relativas à educação pública, constituiu, como vimos, uma das linhas de força do "ciclo das reformas". A situação actual é bastante híbrida, coexistindo, ainda, um quadro político e administrativo com forte protagonismo estatal e uma organização burocrática, com uma retórica descentralizadora, liberal e modernizadora. Neste contexto, têm vindo a ser tomadas, em particular desde os meados da década de 90 do século passado, diversas medidas avulsas que vão no sentido (pelo menos discursivo) de uma substituição de um "controlo pelas normas" por um "controlo pelos resultados", com o reforço da participação local e da autonomia das escolas e a criação de múltiplos dispositivos de avaliação. Irei apresentar, de seguida, um breve inventário dessas medidas e uma caracterização da situação existente no início de 2003, em alguns dos domínios onde são mais notórios esses novos modos de regulação, estabelecendo igualmente a sua relação com o processo de produção/combate às desigualdades. ${ }^{14}$

\section{Ocurrículo}

O currículo é definido centralmente, contudo estão previstas algumas áreas curriculares de livre organização pela escola. Por exemplo, as escolas podem: fazer variar a carga horária das diferentes componentes do currículo, dentro de limites pré-estabelecidos; definir os conteúdos e organizar as áreas curriculares não-disciplinares previstas no $2^{\circ}$ e $3^{\circ}$ ciclos; propor a criação de cursos tecnológicos no ensino secundário; conceber, propor e gerir medidas de diversificação curricular para alunos com insucesso escolar ou necessidades educativas especiais; criar e organizar cursos de educação e formação profissional para os alunos que terminam a escolaridade obrigatória (com ou sem aproveitamento) e não prosseguem estudos.

No domínio curricular a "autonomia" reside fundamentalmente no nível da escola e de seus órgãos de gestão, sendo pouco relevante, do ponto de vista institucional, o papel desempenhado pelas autarquias e por outras entidades locais. Contudo, é de registar a oferta, por muitos municípios, de programas socio-educativos e actividades de ocupação de tempos livres que, não fazendo parte do currículo oficial, acabam por ter um sentido complementar. 
A uma maior flexibilização da gestão do currículo por parte das escolas correspondeu um reforço dos dispositivos de controlo das aprendizagens e dos resultados escolares, por parte da administração central e regional do Ministério da Educação, principalmente por meio da reintrodução e generalização dos exames e das provas de avaliação externa e interna. Tendo sido praticamente abolidos na sequência da revolução de 1974, os exames são progressivamente reintroduzidos no período de normalização e generalizados a todo o sistema a partir da década de 1990. Foi criado um organismo no Ministério da Educação para controlar todo este processo, o Gabinete de Avaliação Educacional (GAVE), ao mesmo tempo que se generaliza a avaliação externa do desempenho das escolas conduzida pelos serviços de Inspecção-Geral da Educação. De assinalar ainda a crescente importância e influência de novos modos de regulação não-institucional, no domínio do currículo, resultantes da pressão comercial dos editores de livros escolares (adoptados livremente pelas escolas), da pressão dos meios de comunicação social para a publicitação dos resultados escolares (ranking das escolas) e da existência de um numerus clausus para acesso ao ensino superior.

As medidas de redução das desigualdades, no domínio do currículo, estão confiadas em grande parte à iniciativa das escolas e constituem um campo específico da sua autonomia. Entre essas medidas se contam: a disponibilização de um crédito global de horas $(7 \%$ do total de horas curriculares) para a realização de actividades de apoio pedagógico aos alunos com dificuldades de aprendizagem; criação de turmas com "currículos alternativos" para alunos com "insucesso escolar repetido" e risco de abandono da escolaridade básica etc.; a "gestão flexível dos currículos" pelas escolas; a possibilidade de criação de cursos para jovens com idades compreendidas entre os 15 e 18 anos ("Programa 15-18") que não concluíram o $3^{\circ}$ ciclo da escolaridade obrigatória. Como medida mais global neste domínio, é ainda de referir a criação em 1996 dos Territórios Educativos de Intervenção Prioritária (TEIP) que são objecto de políticas de "discriminação positiva" à semelhança das ZEP francesas. Todas essas medidas acabam por ter um efeito essencialmente "paliativo" que, não atacando a raiz do processo de produção das desigualdades, deixa às iniciativas das escolas a tarefa de "pacificação" escolar e social.

\section{Oferta escolar}

Desde os anos de 1980 que se assiste, progressivamente, a uma passagem de uma regulação centralizada, por intermédio de uma carta 
escolar elaborada nacionalmente, para uma regulação mais descentralizada por meio de cartas escolares municipais elaboradas pelas autarquias. Neste momento ainda são poucos os municípios que elaboraram a sua carta escolar, mas essa obrigação decorre de uma lei recentemente aprovada. Até ao presente as autarquias municipais só têm a responsabilidade de construção escolar para o $1^{\circ}$ ciclo do ensino básico (do $1^{\circ}$ ao $4^{\circ}$ ano de escolaridade), mas está prevista a extensão dessa responsabilidade até ao final da escolaridade obrigatória $\left(2^{\circ}\right.$ e 3 ciclos do ensino básico), no quadro de um processo de descentralização actualmente em curso.

No ensino básico (escolaridade obrigatória) a inscrição dos alunos em escolas públicas faz-se em função da "proximidade da área de residência, ou da actividade profissional dos pais”, devendo ser assegurada ao longo de todo o ciclo de escolaridade. No ensino secundário a escolha da escola faz-se em função dos cursos ou fileiras que o aluno deseja frequentar (pois nem todas as escolas oferecem as mesmas opçôes). Num caso e noutro, sempre que numa escola há uma procura maior do que a oferta, as vagas deverão ser preenchidas de acordo com a seguinte ordem de prioridades: alunos que frequentaram a escola no ano lectivo anterior; alunos com necessidades educativas especiais; alunos com irmãos já matriculados na mesma escola; alunos cuja residência ou lugar de trabalho dos pais se situa na área de influência da escola. Nas situações em que a oferta de escolas públicas do ensino básico (obrigatório) não é suficiente, o Ministério da Educação pode realizar contratos de associação com escolas privadas que ficam sujeitas aos mesmos critérios.

Assiste-se a uma progressiva passagem de uma "regulação da procura" pela oferta, a uma "regulação da oferta" pela procura. Isso significa que a regulação institucional pela carta escolar e pela sectorização (obrigação de os alunos frequentarem a escola do seu local de residência) vai sendo "subvertida" por formas de regulação mais autónomas, produzidas no contexto situacional. Essas formas de regulação resultam, essencialmente, do jogo da procura social e das estratégias das famílias, em particular da classe média, que desejam escolher escolas ou itinerários escolares com maiores possibilidades de sucesso e mobilidade social. De registar, ainda, o aparecimento, ainda muito reduzido, de estratégias de promoção de cursos e escolas, no ensino secundário, para atracção de alunos, bem como a influência que a especialização (actualmente em curso) de escolas em determinadas fileiras do ensino secundário irá determinar no fluxo dos alunos. Finalmente, é de sublinhar 
nestas novas formas de regulação do fluxo dos alunos o peso progressivamente maior do ensino privado, particularmente no ensino secundário, na tentativa que os alunos e suas famílias fazem para beneficiar-se de maiores facilidades na obtenção de classificações mais elevadas que permitam melhorar a sua nota de acesso ao ensino superior.

A produção de desigualdades nos fluxos escolares dos alunos resulta quer das dificuldades económicas dos alunos para frequentarem a escola (incluindo custos de acessibilidade e manque à gagner), quer da influência, nos percursos escolares e na escolha da escola, de factores económicos, sociais ou geográficos. No primeiro caso, as medidas de redução das desigualdades que foram adoptadas destinam-se a prestar apoio socio-económico aos alunos e a suas famílias (transportes, material escolar e alimentação), considerado, em geral, muito insuficiente. No $1^{\text {o }}$ ciclo do ensino básico a responsabilidade desse apoio cabe às autarquias municipais e nos outros ciclos, à administração central, excepto nos transportes, que também é da competência das autarquias. No segundo caso, apesar de existir a sectorização ela é frequentemente posta em causa, por meio de múltiplas estratégias, pelas famílias melhor posicionadas económica e socialmente.

\section{Professores (recrutamento e formação)}

Os professores são funcionários públicos sendo recrutados pelo Ministério de Educação por intermédio de um concurso nacional. A possibilidade de transferir para as autarquias municipais (e, em certas condições, para as escolas) a responsabilidade pelo recrutamento e pela colocação dos professores tem sido radicalmente contestada pelos professores e por suas organizações sindicais, e parece não seduzir os eleitos locais. A formação inicial está a cargo das instituições de ensino superior (públicas e privadas), mas, segundo legislação recente, os cursos deverão ser acreditados por um organismo (INAFOP) criado especificamente para esse fim. ${ }^{15}$ A formação contínua é, formalmente, bastante descentralizada, podendo ser organizada por instituiçôes do ensino superior, associações de professores, serviços do Ministério da Educação e pelos Centros de Formação de Associações de Escolas. Esses centros foram criados em 1993 na sequência da aprovação do PRODEP (programa de financiamento da educação integrado no "quadro comunitário de apoio" da União Europeia). Embora consagrem, formalmente, uma larga autonomia às escolas associadas na 
organização e gestão da formação contínua dos seus professores, a sua acção acaba por estar muito condicionada pela dependência que têm das verbas do PRODEP e pelas regras de acreditação definidas por um Conselho Coordenador da Formação Contínua (Barroso \& Canário, 1999).

Se no caso do recrutamento se mantêm as formas tradicionais de controlo de um sistema centralizado, no caso da formação inicial e contínua a situação tem-se revelado diferente. No caso da formação inicial, onde existia uma regulação institucional débil por parte da administração central (assente quase exclusivamente na definição dos requisitos para a entrada na carreira e no controlo do estágio profissional), assiste-se a um reforço de controlo da própria oferta e dos cursos de formação, por intermédio das normas e dos critérios de acreditação. No caso da formação contínua, pelo contrário, verifica-se que, por detrás de uma retórica de descentralização e de autonomia das escolas, tem-se desenvolvido, na prática, um reforço do controlo (ainda que indirecto), em consequência do sistema de financiamento, das normas de acreditação das acções de formação e da incidência que essa formação tem na progressão da carreira dos professores.

As principais medidas de redução das desigualdades, neste domínio, passam pelo reforço de docentes (professores de apoio) em determinados contextos escolares, nomeadamente no $1^{\circ}$ ciclo e nos Territórios Educativos de Intervenção Prioritária. Insere-se igualmente nessas medidas a disponibilização de um crédito horário docente, em escolas do $2^{\circ}$ e $3^{\circ}$ ciclos e do secundário, para a realização de projectos específicos e apoio pedagógico a alunos. Esta é uma das razões (juntamente com a redução do número de alunos por turma) para o facto de, nos últimos anos, apesar de se ter assistido a uma redução global dos efectivos escolares, o número de professores ter aumentado substancialmente.

\section{Gestão escolar e recursos financeiros}

No nível da gestão escolar tem-se assistido a um progressivo reforço das competências das entidades locais, em particular das escolas e, em menor grau, das autarquias. Do ponto de vista das estruturas, esse reforço é visível na legislação sobre autonomia e gestão escolar, que começou a ser aprovada a partir dos finais da década de 1980. No que se refere às escolas, esse reforço passa nomeadamente: pela possibilidade de as escolas escolherem os seus dirigentes (em vigor desde a revolução de 
1974); pela capacidade de definirem o seu projecto educativo e regulamento interno (dentro de limites estabelecidos pela lei geral); pela existência de uma relativa margem de escolha na organização interna da escola, no nível da composição dos órgãos de gestão de topo e intermédia; por uma relativa flexibilização orçamental, nomeadamente no nível da gestão de recursos humanos e financeiros; pela possibilidade de disporem de receitas próprias geradas por aluguer de instalações, venda de serviços e cobrança de certas taxas etc. Quanto às autarquias, elas passaram a intervir nos órgãos de gestão das escolas e devem constituir órgãos consultivos de gestão municipal para a educação (os Conselhos Locais de Educação), embora no essencial ainda estejam bastante longe de ter uma intervenção activa, quer por falta de dotaçôes orçamentais, quer pelo facto de as leis da descentralização estarem ainda por regulamentar. $\mathrm{O}$ Ministério da Educação é assim o principal responsável pelo financiamento público da educação, sendo o financiamento das autarquias muito limitado (inferior a 3\% em 1992).

$\mathrm{O}$ reforço da autonomia das escolas previsto na legislação é muito condicionado pelo exercício do poder das estruturas desconcentradas do Ministério da Educação (Direcções Regionais da Educação), pela produção de inúmeras normas regulamentadoras por parte dos diversos serviços da administração, pelas práticas burocráticas ainda existentes e por uma cultura de dependência que marca ainda muitas escolas. Além disso, até ao momento (e com as limitações referidas), a autonomia limita-se aos aspectos organizativos, faltando uma definição clara das competências e dos recursos que serão transferidos para os órgãos de governo das escolas. ${ }^{16} \mathrm{~A}$ este propósito é de referir que alguns dos instrumentos fundamentais para essa definição, como sejam os "contratos de autonomia" a realizar entre as escolas, as autarquias e os serviços desconcentrados da administração, ainda não foram regulamentados. Contudo, apesar de o reforço da autonomia ainda estar numa fase muito incipiente, não deixou de se fazer sentir, nos últimos anos, o aparecimento de novas modalidades de regulação baseadas num reforço dos dispositivos de avaliação externa das escolas, postos em prática pelos serviços da Inspecção.

Do ponto de vista do acesso, as medidas de redução das desigualdades traduziram-se essencialmente num alargamento e na renovação do parque escolar que, apesar do seu notável desenvolvimento, ainda apresenta, principalmente nas periferias urbanas, graves situações de carências e de sobre-ocupação. Quanto às medidas de redução das desigualdades de sucesso escolar e "combate à exclusão", elas caracteri- 
zam-se por serem muito desarticuladas, esporádicas e meramente paliativas. De registar, contudo, o reforço de meios (humanos e financeiros) subjacente à criação dos Territórios Educativos de Intervenção Prioritária (TEIPS), bem como a existência de múltiplas linhas de financiamento (com origem em diferentes serviços e entidades do Ministério da Educação) para projectos sectoriais no domínio da inovação e no combate ao insucesso escolar, de que o Programa de Educação para Todos (PEPT) foi um dos exemplos mais conhecidos. Esta política de apoio a projectos apresentados pelas escolas tem o aspecto positivo de promover a iniciativa das escolas e adaptar as políticas financeiras aos contextos escolares, mas, para além da insuficiência de meios, tem revelado a ausência de uma estratégia global e de uma optimização de meios. De assinalar, ainda, o envolvimento das autarquias no financiamento deste tipo de projectos e o desenvolvimento de iniciativas próprias no domínio socio-educativo (Guedes, 2002).

\section{Partenariado}

Segundo a legislação aprovada em 1998 sobre a autonomia e gestão escolar, a "Assembleia de Escola" integra (para além de professores, pessoal não-docente e alunos) os representantes dos pais dos alunos, das autarquias e de interesses económicos e culturais locais. Contudo, essa representação é minoritária e o recrutamento dos representantes dos pais faz-se essencialmente junto de grupos sociais reduzidos (classe média) e em particular de pais e mães que são professores. Para além desta participação formal e institucional, muito limitada, é frequente as escolas desenvolverem estratégias de angariação de fundos e de apoio aos seus projectos, junto dos pais, das autarquias locais e de empresas, criando por vezes redes activas de partenariado. Nas escolas secundárias com cursos tecnológicos é frequente haver uma articulação com as empresas da região, quer para a definição da própria oferta de cursos quer para o desenvolvimento de estágios para os alunos. Ainda neste domínio, é de salientar a criação, em 1989, das "escolas profissionais" que fornecem cursos de natureza profissional, de nível III (três anos após o ensino obrigatório), com grande autonomia curricular, embora condicionada a um enquadramento global definido pelo Ministério da Educação, a que é dada equivalência ao ensino secundário. A criação dessas escolas é de iniciativa de diferentes promotores (independentes ou associados), quer públicos ou privados, com destaque para as câmaras municipais, empresas privadas, associações 
patronais e sindicais. Inicialmente grande parte dessas escolas era subsidiada por fundos públicos, em particular da União Europeia, mas hoje elas têm que garantir o seu auto-financiamento.

É no sector da formação profissional que mais se verifica a influência da política da União Europeia na regulação do sistema educativo. Esta nova forma de regulação supranacional se tem vindo agravar principalmente desde o Tratado de Maastricht e tem vindo a conhecer novos desenvolvimentos no ensino superior, após a Declaração de Bolonha, o que não deixará de ter influência, por arrastamento, nos níveis de ensino inferiores. Do mesmo modo, a articulação da educação à lógica económica e a intensificação das parcerias com as empresas, que constituem uma das "racionalidades do discurso educativo de Bruxelas" (Nóvoa, 1998), produzem constrangimentos claros (e efeitos de homogeneização) na regulação institucional dos diferentes países europeus. No caso português, estes novos modos de regulação que resultam das influências das famílias e das empresas do sector privado ainda são incipientes ou emergentes, mas têm vindo a ganhar uma projecção crescente nos últimos anos, patente, nomeadamente, na incorporação no discurso oficial de temas como "controlo da qualidade", "promoção da excelência", "estímulo da competitividade", "livre escolha" etc., tão caros ao discurso neo-liberal.

O aumento da participação dos pais na escola e na sua gestão não se tem traduzido de uma maneira clara na redução das desigualdades escolares, atendendo, como já foi dito, ao reduzido campo social donde são recrutados. De qualquer modo, pelo carácter recente dessas medidas, ainda é cedo para avaliar correctamente o seu impacto. De registar contudo que, do ponto de vista formal, foram ensaiadas algumas tentativas tímidas de criação de condições para que a participação parental se intensifique e se diversifique, nomeadamente por intermédio de legislação que prevê a justificação de faltas (e em alguns casos mantendo o direito à retribuição salarial), para os pais que exercem cargos de gestão nas associações ou nas escolas poderem participar em reuniōes. Quanto ao envolvimento de entidades ligadas às empresas, tal iniciativa está relacionada essencialmente ao desenvolvimento da formação profissional. Embora o discurso oficial seja de reforçar o prestígio social dessa formação, o certo é que, para a opinião pública, para os alunos e suas famílias, esses cursos aparecem como uma forma desvalorizada de percurso escolar destinada aos que não querem estudar e aos que dispóem de menores recursos. 


\section{A “contaminação" internacional}

A descrição e análise que efectuei, no presente artigo, sobre a evolução recente do sistema educativo português permitiu dar conta das transformaçōes que ocorreram não só em determinados domínios do seu funcionamento, mas em particular no modo como o Estado tem exercido a sua função de coordenação e controlo, no quadro do que se definiu como "regulação institucional". Este tipo de abordagem se justifica pelo papel central que o Estado e a sua administração continuam a desempenhar, em Portugal, na definição e execução das políticas educativas, pese embora o discurso reformista em vigor desde os meados dos anos 80 do século passado, essencialmente orientado para a redução da sua intervenção e para a "modernização" da sua administração.

A situação actual caracteriza-se, como já foi dito, por uma aceleração do discurso e das práticas políticas que configuram o desenvolvimento de uma "regulação mercantil", resultante não só da nova conjuntura política (governo de maioria centro-direita), mas principalmente de um contexto internacional favorável a este tipo de regulação.

Importa, por isso, analisar as características desse contexto e o modo como se processa a "contaminação" que existe no nível da transferência dos conceitos, das políticas e das medidas postas em prática, entre os países, em escala mundial (ver a este propósito Barroso et al., 2002, e Barroso, 2003).

A problemática da reforma e reestruturação do Estado constitui, principalmente a partir dos anos 80 do século XX, um tema central do debate político, num conjunto alargado de países, em todos os continentes, e está na origem de medidas legislativas, muito diversas, que afectaram a administração pública em geral e, consequentemente, a educação (Afonso, 2003).

É no contexto deste debate que, na educação, promovem-se, discutem-se e aplicam-se medidas políticas e administrativas que vão, em geral, no sentido de alterar os modos de regulação dos poderes públicos no sistema escolar (muitas vezes com recurso a dispositivos de mercado), ou de substituir esses poderes públicos por entidades privadas, em muitos dos domínios que constituíam, até aí, um campo privilegiado da intervenção do Estado. Essas medidas tanto podem obedecer (e serem justificadas), de um ponto de vista mais técnico, em função de critérios de modernização, desburocratização e combate 
à "ineficiência" do Estado (new public management), como serem justificadas por imperativos de natureza política, de acordo com projectos neoliberais e neo-conservadores, com o fim de "libertar a sociedade civil" do controlo do Estado (privatização), ou mesmo de natureza filosófica e cultural (promover a participação comunitária, adaptar ao local) e de natureza pedagógica (centrar o ensino nos alunos e suas características específicas).

A coexistência em vários países (de contextos geopolíticos tão diferentes) de discursos e medidas semelhantes indicia fenómenos de convergência que resultam, por um lado, dos processos de integração supranacional das economias e das políticas (conhecidos pela designação de "mundialização" ou "globalização") e, por outro lado, da permeabilidade do discurso político às retóricas de legitimação difundidas pelos centros de decisão e difusão internacionais, por meio daquilo que chamo de "efeito de contaminação".

Uma explicação para este "efeito de contaminação" pode ser dada pelo facto de, como diz Walford (2001), funcionários, membros do governo e educadores terem tendência a adoptar soluçōes transportáveis, em uso num determinado país, para aplicarem nos seus próprios sistemas educativos:

(...) olhar para os sistemas educativos de outros países e observar aquilo que funciona exerce uma atraç̧ão evidente nos decisores políticos em busca de soluçôes rápidas que lhes permitam evitar as dificuldades, ou legitimar, por meio delas, as mudanças que propõem para os seus sistemas. (Walford, 2001, p. 179)

Este processo, a que Walford (à semelhança de Halpin \& Troyna, 1995) chama de educational policy borrowing (empréstimo de políticas educativas), é comum a outros períodos históricos e conhece hoje um incremento maior, não só pela internacionalização dos fóruns de consulta e decisão política, mas também pela importância crescente das agências internacionais (lideradas pelos "países centrais") nos programas de cooperação destinadas aos "países da periferia".

Contudo, se esse "empréstimo" é, por vezes, meramente retórico e destinado a legitimar, com o exemplo estrangeiro, soluçōes internas, outras vezes ele resulta de uma convergência real com finalidades políticas mais vastas (Ball, 1998). É o que acontece actualmente no contexto da chamada "globalização" (ver a este propósito Burbules \& Torres, 2000). É o que acontece igualmente, e no mesmo contexto, 
com a acção de organismos como a OCDE, de que Bajomi (2002) nos dá um bom e recente exemplo, reportando-se à situação dos países do Centro e Leste da Europa. Ou, ainda, o Fundo Monetário Internacional e o Banco Mundial que, como afirma Oliveira (2000), falando do caso do Brasil, fazem da educação pública um instrumento da "gestão do trabalho e da pobreza". O mesmo acontece com os "programas de ajustamento estrutural" do Banco Mundial, destinados a impor a "descentralização como mecanismo de reestruturação do Estado", como é visível na análise que Kamat (2000) faz do relatório desta organização, intitulado Beyond the center: decentralization the State (Burki, Perry \& Dillinger, 1999).

Neste sentido, podemos dizer que a globalização se transforma numa "regulação transnacional" e a regulação nacional numa espécie de "globalização de baixa intensidade". ${ }^{17}$

Contudo, como é visível em vários dos estudos comparados acima mencionados, se estes conceitos de "policy borrowing" ou de "globalização" podem ser úteis para explicar as "similitudes" no nível macro da retórica e das reformas políticas, eles mascaram e falseiam a diversidade de políticas efectivas que são postas em prática, suas origens e efeitos.

Por um lado, como refere Van Zanten (2000), porque “(..) apesar das pressóes globalizantes, verificam-se diferenças nacionais importantes que resultam do facto de a corrente liberal, como todas as novas influências, agir em interacção com as ideologias e estruturas já existentes" (p. 357).

Por outro lado, como refere Derouet (2002), porque "se as palavras de ordem [descentralização e autonomia das escolas] são as mesmas em toda a parte, os que as põem em prática se referem a justificações diferentes conforme as instituiçóes" (p. 10).

Finalmente, como assinala Walford (2001) a propósito do estudo das políticas de privatização nos países industrializados: "Estas mudanças só podem ser compreendidas a partir de um conhecimento adequado do contexto social, histórico, económico e político em que elas são desenvolvidas e postas em prática” (p. 194), o que obriga a uma abordagem do nível micro, tendo em vista o mapeamento dos processos e estudos de caso específicos.

Como último elemento de análise deste fenómeno de "contaminação" e "empréstimo" pelo qual se dá a internacionalização das políticas educativas, é importante referir, ainda, o processo de "externalização" que, 
segundo alguns autores (Schriewer, 2001; Steiner-Khamsi, 2002), explica o "sucesso" que a importação/exportação de modelos de reforma tem hoje no domínio educativo. De acordo com esta perspectiva (baseada na "teoria dos sistemas sociais auto-referenciais" de Luhmann) o recurso sistemático a referências internacionais, às "lições que vêm de fora", tem como principal função suprir, na argumentação política, a insuficiência ou deficiência dos exemplos nacionais (tradiçỗes, crenças, formas de organização). Como diz a este propósito Steiner-Khamsi (2002):

Em épocas de rápidas mudanças sociais, económicas e políticas, as referências internas são insuficientes para justificar a persistência ou a introdução de reformas. É precisamente nesses momentos que a externalização oferece a oportunidade de romper radicalmente com o passado e importar, ou tomar como empréstimo, modelos, discursos ou práticas de outros sistemas educativos". (P. 70)

Como explica Schriewer (2001), neste contexto, as referências às "situações mundiais" cumprem simultaneamente funções de justificação (de valores e ideologias), de auto-legitimação (dos estudos educacionais como campo académico) e de imputação (dos fracassos das reformas) e podem ser trazidas a lume para vários argumentos políticos.

Consequentemente, e do ponto de vista metodológico, as externalizações com recurso a situações mundiais não são intentadas com vista à produção de conhecimento sociológico, a partir de estudos comparados sobre configuraçōes culturais distintas. Tais externalizações implicam antes uma interpretação avaliativa dos dados, estruturas ou questōes internacionais visando à extracção de argumentos que sejam "relevantes" para as políticas e práticas educativas. (P. 17)

Neste sentido, a importância que as referências à situação internacional assumem, no quadro das discussóes de política interna, não decorre tanto do valor intrínseco dos acontecimentos invocados (reformas, inovações, estruturas), mas mais do seu valor explicativo como síntese do que se pretende considerar como mais conveniente para pôr em prática no próprio país.

É à luz desta perspectiva que deve ser lida a caracterização que fiz das mudanças que ocorreram recentemente na organização e regulação dos ensinos básico e secundário em Portugal, bem como os sentidos das transformações que se avizinham.

Recebido e aprovado em fevereiro de 2003. 


\section{Notas}

1. O ensino básico em Portugal corresponde aos nove anos de escolaridade obrigatória e está dividido em três ciclos: $1^{\circ}$ ciclo de quatro anos e professor único; $2^{\circ}$ ciclo de dois anos e professor por disciplinas; $3^{\circ}$ ciclo de três anos e professor por disciplinas. $\mathrm{O}$ ensino secundário não é obrigatório e abrange o $10^{\circ}, 11^{\circ}$ e $12^{\circ}$ anos de escolaridade.

2. Trata-se do projecto Reguleducnetwork ("Changes in regulation modes and social production of inequalities in education systems: a European comparison"), subsidiado pela Comissão Europeia, no âmbito do programa "Improving the socio-economic knowledge base". Este projecto decorre até outubro de 2004 e os seus relatórios parcelares podem ser consultados na página web do Centro de Estudos da Escola: <www.fpce.ul.ptlcentroslceescola>.

3. Entre os exemplos mais significativos deste tipo de estudos são de citar: Almerindo Afonso (1997 e 2000), Natércio Afonso (1994), Barroso (1995), Formosinho, Ferreira \& Machado (2000), Lima (1998, 1999 e 2000).

4. Entre os exemplos mais significativos deste tipo de estudos são de citar: Stoer (1986), Correia (1999), Gomes (1999) e Teodoro (2001a).

5. Esta "classificação" é sustentada, no que se refere aos três primeiros ciclos, nos trabalhos de diferentes autores que se debruçaram sobre a análise das políticas educativas a seguir após 1974, em particular Stoer (1982 e 1986) e Teodoro (2001a).

6. A expressão "normalização", para referir o período que se seguiu ao primeiro governo constitucional, foi utilizada por Grácio em 1978 (ver Grácio, 1995, p. 392) e posteriormente desenvolvida por Stoer (1982 e 1986) na análise que faz da política educativa nesse período.

7. Partilho da opinião de António Teodoro (2001a, p. 391) ao considerar a aprovação da Lei de Bases do Sistema Educativo um marco preferencial para assinalar o fim do período da "normalização", não só pelo seu significado específico no domínio da política educativa, mas pelo contexto político interno (o Partido Socialista perde a maioria para o Partido Social-Democrata que vai estar no poder até 1996) e externo (integração de Portugal na Comunidade Europeia).

8. Para uma análise desse período, consultar igualmente Afonso (2000) e Lima (2000).

9. Sobre a emergência de uma perspectiva neo-liberal na construção da política educativa nesse período, consultar Afonso (2000) e Marques Cardoso (2001 e 2003).

10. Sobre as escolas profissionais, consultar, entre outros, Antunes (2001).

11. Consultar a este propósito Canário, 2000; Canário, Alves \& Rolo (2001).

12. Para um balanço da evolução do sistema educativo português entre 1986 e 1996, nomeadamente no que se refere ao impacto do PRODEP I, consultar o conjunto de estudos editados pelo Departamento de Avaliação e Prospectiva do Ministério da Educação (DAPP), sob o título genérico de "A evolução do sistema educativo e o PRODEP", em 1998.

13. Trata-se de um estudo encomendado pelo ministro da Educação, em 1998, a uma equipa coordenada por Roberto Carneiro, e que foi publicado, em 2001, pelo Departamento de Avaliação e Prospectiva. Esse estudo identifica as tendências da evolução recente do sistema educativo e traça um conjunto de cenários prospectivos para o horizonte do ano de 2020.

14. Essa caracterização se baseia nas análises efectuadas por João Barroso, Natércio Afonso, Rui Canário, Luís Leandro Dinis, Berta Macedo e João Pinhal, no âmbito do projecto de investigação Reguleducnetwork (Barroso et al., 2002).

15. Esse instituto foi extinto pelo actual governo e as suas funçôes foram integradas em outros órgãos da administração central.

Educ. Soc., Campinas, vol. 24, n. 82, p. 63-92, abril 2003

Disponível em <http://www.cedes.unicamp.br> 
16. Para uma caracterização da situação existente em Portugal, neste domínio, consultar os Relatórios da avaliação externa, disponíveis em <www.fpce.ul.pt|centroslceescola > e, em particular, Barroso, 2001.

17. Para utilizar a feliz expressão de Teodoro (2001b), num texto em que é analisada a influência das organizaçóes internacionais na política educativa portuguesa, expressivamente intitulado "Organizaçōes internacionais e políticas educativas nacionais: a emergência de novas formas de regulação transnacional, ou uma globalização de baixa intensidade".

\section{Referências bibliográficas}

AFONSO, A.J. O neoliberalismo educacional mitigado numa década de governação social-democrata: um contributo sociológico para pensar a reforma educativa em Portugal (1985-1995). Revista Portuguesa de Educação, Braga, v. 10, n. 2, p. 103-137, 1997.

AFONSO, A.J. Políticas educativas em Portugal (1985-2000): a reforma global, o pacto educativo e os reajustamentos neo-reformistas. In: Catani, A.; Oliveira, R. (Org.). Reformas educacionais em Portugal e no Brasil. Belo Horizonte: Autêntica, 2000.

AFONSO, N. A reforma da administração escolar: a abordagem política em análise organizacional. Lisboa: Instituto de Inovação Educacional, 1994.

AFONSO, N. A regulação da educação na Europa: do Estado educador ao controlo social da escola pública. In: BARROSO, J. (Org.). A escola pública: regulação, desregulação, privatização. Porto: ASA, 2003.

ANTUNES, F. Os locais das escolas profissionais: novos papéis para o Estado e a europeização das políticas educativas. In: STOER, S.R.; CortesÃo, L.; Correia, J.A. (Org.). Transnacionalização da educą̧ão: da crise da educação à "educação" da crise. Porto: Afrontamento, 2001.

BAJOMI, I. Points communs et divergences. In: Bajomi, I.; Derouet, J.-L. (Dir.). La grande récréation: la décentralisation de l'éducation dans six pays autrefois communistes. Paris: INRP, 2002.

BALL, S. Big policies/small world: an introduction to international perspectives in education policy. Comparative Education, Oxford, v. 34, n. 2, p. 119-130, 1998.

BARROSO, J. Do mito da reforma à reforma de um mito. Aprender, Portalegre, n. 2, p. 12-18, jun. 1987. 
BARROSO, J. Estratégias de reforma. Seara Nova, Lisboa, n. 18, p. 8-11, jun./jul. 1988.

BARROSO, J. Os liceus: organização pedagógica e administração (18361960). Lisboa: Junta Nacional de Investigação Científica; Fundação Calouste Gulbenkian, 1995. 2v.

BARROSO, J. Do pacto educativo à educação como pacto. In: TEODORO, A. (Coord.). Pacto educativo: aspirações e controvérsias. Lisboa: Texto, 1996. P. 79-89.

BARROSO, J. O século da escola: do mito da reforma à reforma de um mito. In: Terrén, E.; Hameline, D.; Barroso, J. O século da escola: entre a utopia e a burocracia. Porto: ASA, 2000.

BARROSO, J. Relatório global da primeira fase do Programa de Avaliação Externa; efectuado no âmbito do programa de avaliação externa do processo de aplicação do regime de autonomia, administração e gestão das escolas e agrupamento de escolas definido pelo DecretoLei $\mathrm{n}^{\circ}$ 115-A/98, de 4 de maio. Disponível em: <http://www.fpce.ul.pt/ centros/ceescola - http://www.fpce.ul.pt/centros/ceescola > Acesso em 2001.

BARROSO, J. et al. Analyse de l'évolution des modes de régulation institutionnalisée dans le système éducatif du Portugal. Lisboa: Faculdade de Psicologia e de Ciências da Educação de Lisboa. Disponível em: <http://www.fpce.ul.pt/centros/ceescola - http://www.fpce.ul.pt/ centros/ceescola> Acesso em 2002.

BARROSO, J. Regulação e desregulação nas políticas educativas: tendências emergentes em estudos de educação comparada. In: BARROSO, J. (Org.). A escola pública: regulação, desregulação, privatização. Porto: ASA, 2003.

BARROSO, J. (Org.). A escola pública: regulação, desregulação, privatização. Porto: ASA, 2003.

BARROSO, J.; CANÁRIO, R. Centros de formação das associações de escolas: das expectativas às realidades. Lisboa: Instituto de Inovação Educacional, 1999.

BURBULES, N.; TORRES, C.A. (Ed.). Globalization and education: critical perspectives. New York: Routledge, 2000.

BURKI, S.; PERRY, G.; DILLINGER, W. Beyond the center: decentralization the State, Latin American and Caribean Studies. 
Washington,D.C.: WorldBank. Disponível em: <http://www.worldbank.org/ html/extdr/offrep/lac/pubs> Acesso em 1999.

CANÁRIO, R. Educação e perspectivas de desenvolvimento do "interior". In: Madureira Pinto, J.; D’Ornelas, R. (Coord.). Perspectivas de desenvolvimento do interior. Lisboa: Imprensa Nacional Casa da Moeda, 1998.

CANÁRIO, R. Territórios educativos de intervenção prioritária: a escola face à exclusão social. Revista de Educação, Lisboa, v. 9, n. 1, p. 125-135, 2000 .

CANÁRIO, R.; ALVES, N.; ROLO, C. Escola e exclusão social. Lisboa: Educa, 2001.

CARNEIRO, R. 2020: 20 anos para vencer 20 décadas de atraso educativo: síntese do estudo. In: Carneiro, R.; Caraça, J.; São Pedro, M. (Coord.). O futuro da educação em Portugal: tendências e oportunidades; um estudo de reflexão prospectiva. Lisboa: Ministério da Educação, 2000. v. 1

CORREIA, J.A. As ideologias educativas nos últimos 25 anos. Revista Portuguesa de Educação, Braga, n. 12, p. 81-110, 1999.

DEROUET, J.-L. La décentralisation dans les sociétés en transition du centre et de l'est de l'Europe: les apports d'un regard éloigné. In: Bajomi, I.; Derouet, J.-L. (Dir.). La grande récréation: la décentralisation de l'éducation dans six pays autrefois communistes. Paris: INRP, 2002.

ESTEVÃO, C. Globalização, metáforas organizacionais e mudança educacional: dilemas e desafios. Porto: ASA, 2002.

FORMOSINHO, J.; FERREIRA, F.I.; MACHADO, J. Politicas educativas e autonomia das escolas. Porto: ASA, 2000.

GODINHO, V. A educação num Portugal em mudança. Lisboa: Cosmos, 1975.

GOMES, R. 25 anos depois: expansão e crise da escola de massas. Educação, Sociedade \& Culturas, n. 11, p. 133-164, 1999.

GRÁCIO, R. Obra completa. Lisboa: Fundação Calouste Gulbenkian, 1995. v.1.

GUEDES, M. G. As politicas educativas municipais da área metropolitana de Lisboa: o caso dos projectos sócio-educativos. 2002. Disserta- 
ção (mestrado) - Faculdade de Psicologia e de Ciências da Educação, Universidade de Lisboa, Lisboa.

HALPIN, D.; TROYNA, B. The politics of educational policy borrowing. Comparative Education, Oxford, v. 31, n. 3, p. 301-310, 1995.

KAMAT, S. Deconstructing the rhetoric of decentralization: the state in educational reform. Current Issues in Comparative Education, v. 2, n. 2, apr. 2000. Disponível em: <http://www.tc.columbia.edu/CICE> Acesso em 2000 .

LIMA, L.C. A escola como organização e a participação na organização escolar. Braga: Universidade do Minho/Instituto de Educação, 1992. (2. ed. 1998).

LIMA, L.C. A administração do sistema educativo e das escolas (1986/ 1996). In: . A evolução do sistema educativo e o PRODEP: estudos temáticos. Lisboa: DAPP; Ministério da Educação, 1998. v. 1, p. 15-95.

LIMA, L.C. E depois de 25 de abril de 1974: centro(s) e periferia(s) das decisões no governo das escolas. Revista Portuguesa de Educação, Braga, v. 12, n. 1, p. 57-80, 1999.

LIMA, L.C. A administração escolar em Portugal: da revolução, da reforma e das decisões políticas pós-reformistas. In: Catani, A.; Oliveira, R. (Org.). Reformas educacionais em Portugal e no Brasil. Belo Horizonte: Autêntica, 2000.

LIMA, L.C.; AFONSO, A.J. Reformas da educação pública: democratização, modernização, neoliberalismo. Porto: Afrontamento, 2002.

MAROY, C.; DUPRIEZ, V. La régulation dans les systèmes scolaires: proposition théorique et analyse du cadre structurel en Belgique francophone. Revue Française de Pédagogie, Paris, n. 130, p. 73-87, jan./mar. 2000.

MARQUES CARDOSO, C. Decentralization, school autonomy and the state in England and Portugal: 1986-1996. 2001. Tese (Ph.D.) London School of Economics and Political Science, University of London, London.

MARQUES CARDOSO, C. Do público ao privado: gestão racional e critérios de mercado, em Portugal e Inglaterra. In: BARroso, J. (Org.). A escola pública: regulação, desregulação, privatização. Porto: ASA, 2003. 
NÓVOA, A. Histoire \& Comparaison: essais sur l'education. Lisboa: Educa, 1998.

OLIVEIRA, D.A. Educação básica: gestão do trabalho e da pobreza. Petrópolis: Vozes, 2000.

PACHECO, J.A. (Org.). Políticas educativas: o neoliberalismo em educação. Porto: Porto, 2000.

SCHRIEWER, J. Formas de externalização no conhecimento educacional. Lisboa: Educa, 2001. (Cadernos Prestige, 5)

STEINER-KHAMSI, G. Reterritorializing educational import: explorations into the politics of educational borrowing. In: NóvOA, A.; LAWN, M. (Ed.). Fabricating Europe: the formation of an education space. London: Kluwer, 2002.

STOER, S. Educação, estado e desenvolvimento em Portugal. Lisboa: Livros Horizonte, 1982.

STOER, S. Educação e mudança social em Portugal: 1970-1980, uma década de transição. Porto: Afrontamento, 1986.

STOER, S.; STOLEROFF, A.; CORREIA, J.A. O novo vocacionalismo na política educativa em Portugal e a reconstrução da lógica da acumulação. Revista Crítica de Ciências Sociais, Coimbra, v. 29, p. 11-53, 1990.

TEODORO, A. (Coord.). Pacto educativo: aspirações e controvérsias. Lisboa: Texto, 1996.

TEODORO, A. A construção política da educação: Estado, mudança social e políticas educativas no Portugal contemporâneo. Porto: Afrontamento, 2001a.

TEODORO, A. Organizaçôes internacionais e políticas educativas nacionais: a emergência de novas formas de regulação transnacional, ou uma globalização de baixa intensidade. In: STOER, S.R.; CorTesão, L.; CorREIA, J.A. (Org.). Transnacionalização da educação: da crise da educação à "educação" da crise. Porto: Afrontamento, 2001b.

VAN ZANTEN, A. Un libéralisme éducatif sans frontières. In: VAN Zanten, A. (Dir.). L'école, l'état des savoirs. Paris: La Découverte, 2000.

WALFORD, G. Privatization in industrialized countries. In: LEVIN, H. (Ed.). Privatizing education: can the marketplace deliver choice, efficiency, equity, and social cohesion? Boulder, Colorado: Westview, 2001. 